\title{
The cone penetration test in unsaturated silty sands
}

\author{
Hongwei Yang ${ }^{1, a}$ and Adrian Russell ${ }^{2}$ \\ ${ }^{1}$ Department of Civil Engineering, The University of Hong Kong, Pokfulam Road, Hong Kong \\ ${ }^{2}$ Centre for Infrastructure Engineering and Safety, School of Civil and Environmental Engineering, The University of New South Wales, \\ Sydney, NSW, Australia, 2052
}

\begin{abstract}
Very little is known about how to interpret the cone penetration test (CPT) when performed in unsaturated soils. The few published studies on the CPT in unsaturated soils have focused on either clean sands or a silt. In this study new results of laboratory-controlled CPTs in an unsaturated silty sand are presented. The silty sand exhibits hydraulic hysteresis and suction hardening. Suction is observed to have a pronounced affect on measured cone penetration resistance. For an isotropic net confining stress of $60 \mathrm{kPa}$ it is observed that higher suctions give rise to cone penetration resistances that are $50 \%$ larger than those for lower suctions. A semi-theoretical correlation is presented that links measured cone penetration resistances to initial relative density and mean effective stress. For this silty sand it is shown that failing to account for suction may result in significant overestimations and unsafe predictions of soil properties from measured cone penetration resistances.
\end{abstract}

\section{Introduction}

The cone penetration test (CPT) is widely used for in-situ characterization of saturated or dry soils for which interpretation methods are well established (e.g. [1]). The CPT is also performed in unsaturated soils yet very little is known about how to interpret the recovered results.

There is evidence that the cone penetration resistance can be significantly influenced by the presence of suction, as observed in [2-3]. However, engineers are left to interpret the CPT conducted in unsaturated soils using correlations developed for saturated and dry soils. This will inevitably lead to unknown errors in estimations of soil properties $([2,4])$. Limited research has been done on the CPT conducted in unsaturated soils and considerable further research is needed to identify the effect of unsaturation on the interpretation of CPT results, both theoretically and experimentally. This is the motivation for the work presented in the paper.

\section{The test soil: Lyell silty sand}

\subsection{Index properties}

The soil used in this study is a decomposed granite from the catchment area of Lyell dam, NSW, Australia. It is classified as a silty sand (SM) according to the Unified Soil Classification System. Index properties are listed in the Table 1, and a particle size distribution curve is shown in Figure 1.

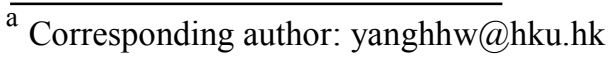

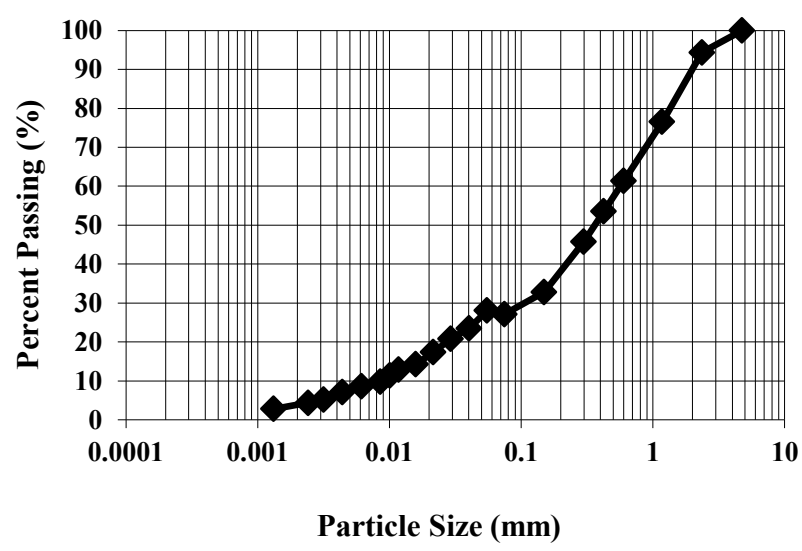

Figure 1. Particle size distribution curve

Table 1. Index properties of Lyell silty sand

\begin{tabular}{ll}
\hline Property & Value \\
\hline Liquid Limit, \% & 15.2 \\
Plastic Limit, \% & N/A \\
Plasticity Index, \% & N/A \\
Specific Gravity & 2.55 \\
Gravel content, \% & 0 \\
Sand content, \% & 73 \\
Fines content, \% & 27 \\
Clay Size Fraction, \% & 4.4 \\
Unified Soil Classification & SM \\
\hline
\end{tabular}

\subsection{Soil-water characteristic curve}

The relationship between void ratio $(e)$, degree of saturation $\left(S_{\mathrm{r}}\right)$ and suction $(s)$ is defined through a soil- 
water characteristic curve (SWCC). $S_{\mathrm{r}}$ on a main drying or wetting curve is ([5]):

$$
S_{\mathrm{r}}=\left\{\begin{array}{ccc}
1 & \text { for } & s \leq s_{\mathrm{e}} \\
\left(\frac{s}{s_{\mathrm{e}}}\right)^{\alpha} & \text { for } & s \geq s_{\mathrm{e}}
\end{array}\right.
$$

where $s_{\mathrm{e}}$ is the $s$ value separating saturated from unsaturated states. For a state on the main drying curve, $s_{\mathrm{e}}$ $=s_{\mathrm{ae}}$, where $s_{\mathrm{ae}}$ is the air entry value. For a state on the main wetting curve, $s_{\mathrm{e}}=s_{\mathrm{ex}}$, where $s_{\mathrm{ex}}$ is the air expulsion value. $\alpha$ is a negative constant. $\alpha$ depends on the pore size distribution. On scanning curves $S_{\mathrm{r}}$ is:

$$
S_{\mathrm{r}}= \begin{cases}\left(\frac{s_{\mathrm{ae}}}{s_{\mathrm{rd}}}\right)^{-\alpha}\left(\frac{s_{\mathrm{rd}}}{s}\right)^{-\beta} & \text { for drying path reversal } \\ \left(\frac{s_{\mathrm{ex}}}{s_{\mathrm{rw}}}\right)^{-\alpha}\left(\frac{s_{\mathrm{rw}}}{s}\right)^{-\beta} & \text { for wetting path reversal }\end{cases}
$$

where $\beta$ is the slope and $s_{\mathrm{rd}}, s_{\mathrm{rw}}$ are the points of suction reversal on the main drying and wetting curves. $s_{\mathrm{ae}}$ depends on $e$ through $s_{\mathrm{ae}}=C_{1} e^{-\gamma}$, in which $C_{1}$ is a positive constant with units of stress and $\gamma$ is a constant. A fixed ratio between $s_{\mathrm{ae}}$ and $s_{\mathrm{ex}}$ is assumed, $s_{\mathrm{ae}}=C_{2} s_{\mathrm{ex}}$, in which $C_{2}$ is a constant. For fractal soils $\gamma=D_{\mathrm{s}}$, where $D_{s}$ is the fractal dimension of the particle size distribution ([6]). As Lyell silty sand is a fractal soil, having fractal particle and pore size distributions, it is found that $s_{\mathrm{ae}}=1.5 e^{-D \mathrm{~s}}$ $\mathrm{kPa}, D_{\mathrm{s}}=2.61$ and $s_{\mathrm{ae}}=30 s_{\mathrm{ex}}$. The fractal dimension of the pore size distribution $\left(D_{\mathrm{p}}\right)$ is 2.48 , meaning $\alpha=D_{\mathrm{p}}$ $3=-0.52$. Scanning curves have slopes $\beta=-0.2$.

\subsection{Effective stress and strengths}

The effective stress approach is adopted here. The effective stress is ([7-8]):

$$
p^{\prime}=p_{\text {net }}+\not s
$$

where $p_{\text {net }}=p-u_{\mathrm{a}}$ is the net stress, $s=u_{\mathrm{a}}-u_{\mathrm{w}}\left(u_{\mathrm{a}}\right.$ and $u_{\mathrm{w}}$ are pore air and water pressures), $\chi$ is the effective stress parameter (having a value of 1 for saturated soils and 0 for dry soils) and $\psi=\mathrm{d}(\chi s) / \mathrm{d} s$. When the state is on a main wetting or drying curve $\chi$ is:

$$
\chi=\left\{\begin{array}{cc}
1 & \text { for } \frac{s}{s_{e}} \leq 1 \\
\left(\frac{s}{s_{e}}\right)^{-\Omega} & \text { for } \quad \frac{s}{s_{e}} \geq 1
\end{array}\right.
$$

where $\Omega$ is a parameter with a best fit value of 0.55 . When the hydraulic state is located on a scanning curve $\chi$ is defined as ([9]):

$$
\chi= \begin{cases}\left(\frac{s_{\mathrm{rd}}}{s_{\mathrm{ae}}}\right)^{-\Omega}\left(\frac{s}{s_{\mathrm{rd}}}\right)^{-\zeta} & \text { for drying path reversal } \\ \left(\frac{s_{\mathrm{rw}}}{s_{\mathrm{ex}}}\right)^{-\Omega}\left(\frac{s}{s_{\mathrm{rw}}}\right)^{-\zeta} & \text { for wetting path reversal }\end{cases}
$$

A triaxial critical state friction angle $\left(\phi_{\mathrm{cs}}^{\prime}\right)$ of $35.7^{\circ}$ was determined for both saturated and unsaturated conditions. The peak friction angle $\left(\phi_{\mathrm{p}}^{\prime}\right)$ observed in the triaxial compression tests (performed with constant cell pressures) on unsaturated samples with constant suctions may be estimated using the expression:

$$
\phi_{\mathrm{p}}^{\prime}-\phi_{\mathrm{cs}}^{\prime}=3\left\{D_{\mathrm{r}}\left(9.5-\ln p^{\prime}\right)-1\right\}
$$

where $D_{\mathrm{r}}$ is the relative density and $p^{\prime}$ is the mean effective stress at the start of shearing with units of $\mathrm{kPa}$.

\section{Cone penetration tests}

The calibration chamber detailed by [10] was used to conduct the laboratory controlled tests. Samples $(460 \mathrm{~mm}$ diameter and $760 \mathrm{~mm}$ height) were prepared using static compaction of soil cured at certain moisture contents ([11]). All the tests were conducted with a penetration rate of $10 \mathrm{~mm} / \mathrm{s}$ at boundary conditions of constant vertical and horizontal stresses.

\begin{tabular}{|c|c|c|c|c|c|}
\hline $\begin{array}{c}\text { Test } \\
\text { number }\end{array}$ & $\begin{array}{c}\text { Compres } \\
\text { sion } \\
\text { Type }\end{array}$ & $\begin{array}{l}\text { Applied } \\
\text { vertical } \\
\text { net } \\
\text { stress } \\
(\mathrm{kPa})\end{array}$ & $\begin{array}{c}\text { Avera } \\
\text { ge } \\
\text { moistu } \\
\text { re } \\
\text { conten } \\
\text { t }\end{array}$ & $\begin{array}{l}\text { Aver } \\
\text { age } s \\
(\mathrm{kPa})\end{array}$ & $\begin{array}{l}\text { Avera } \\
\text { ge } q_{\mathrm{c}} \\
\text { (MPa) }\end{array}$ \\
\hline UL60SAC & Isotropic & 60 & $4.65 \%$ & 24 & 2.17 \\
\hline UL60S100 & Isotropic & 60 & $5.34 \%$ & 37 & 3.26 \\
\hline UL60S300 & Isotropic & 60 & $3.93 \%$ & 72 & 3.36 \\
\hline UL120SAC & Isotropic & 120 & $4.50 \%$ & 31 & 4.50 \\
\hline UL120S100 & Isotropic & 120 & $5.65 \%$ & 37 & 5.24 \\
\hline UD120SAC & Isotropic & 120 & $6.40 \%$ & 13 & 7.80 \\
\hline $\begin{array}{c}\text { UD120S10 } \\
0\end{array}$ & Isotropic & 120 & $4.83 \%$ & 55 & 10.50 \\
\hline UL240SAC & Isotropic & 240 & $4.40 \%$ & 38 & 8.98 \\
\hline UL240S100 & Isotropic & 240 & $5.41 \%$ & 47 & 8.73 \\
\hline K60S100-1 & $\begin{array}{c}\sigma_{\mathrm{h}} / \sigma_{\mathrm{v}}= \\
1.67\end{array}$ & 60 & $5.30 \%$ & 42 & 5.45 \\
\hline K60S100-N & $\begin{array}{c}\sigma_{\mathrm{h}} / \sigma_{\mathrm{v}}= \\
1.67\end{array}$ & 60 & $5.68 \%$ & 34 & 4.97 \\
\hline
\end{tabular}

Test conditions and results are summarized in Table 2 ([12]). The average values are for depths between $0.3 \mathrm{~m}$ to $0.5 \mathrm{~m}$ where $q_{\mathrm{c}}$ profiles are approximately constant, as shown in Figure 2.

Table 2 Tests conducted and relevant conditions

Suction equilibrium was not reached in samples subjected to axis translation ([13]), the SWCC with hydraulic hysteresis and the moisture contents of the samples measured after a CPT was conducted were used to infer suctions. In other samples, the suction values were measured by three vibrating wire piezometers.

Comparing the results for various net confining stress magnitudes reveals that the contribution of suction to 
cone penetration resistance becomes more significant as the confining stress decreases ([14]).

Saturated CPTs in samples at void ratios comparable to those used in unsaturated CPTs were not conducted. This would have required an impractical amount of time to saturate a sample due to its low hydraulic conductivity (being around $3 \times 10^{-7} \mathrm{~m} / \mathrm{s}$ at saturated states) ([13]). Also as unsaturated Lyell silty sand collapses in volume when it becomes saturated this would render the application of vertical stress in the calibration chamber inaccurate due to contact loss between the chamber top plate and the sample. However, a theoretical analysis provides some compensation for this lack of data for the saturated condition, which will be elaborated on in the following sections.

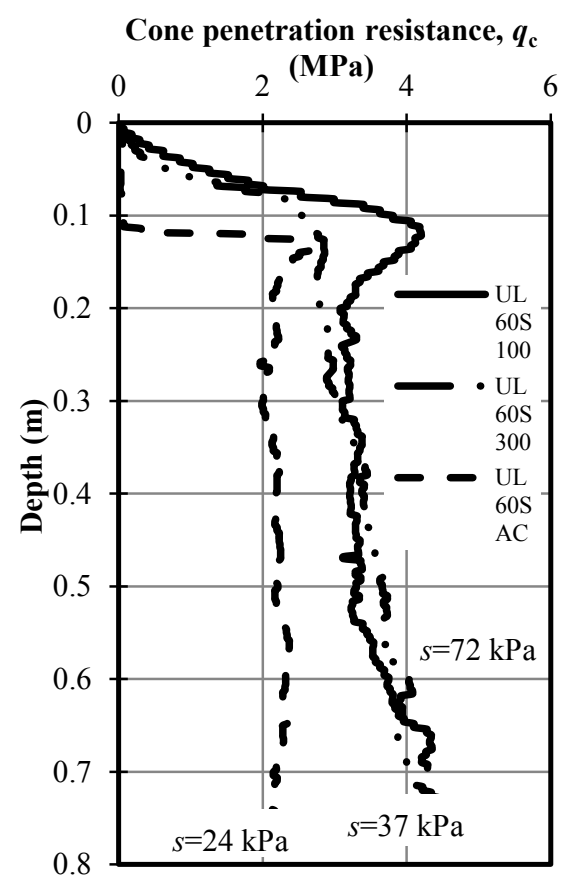

Figure 2. Cone penetration resistance $\left(q_{\mathrm{c}}\right)$ versus depth for samples at isotropic confining pressures of $60 \mathrm{kPa}$ with different suction values.

\section{Interpretation of the CPT results}

\subsection{Cavity expansion solutions}

The cavity expansion problem is an analog to the CPT. The pressure at the wall of an expanding spherical cavity $\left(\sigma_{\mathrm{L}}\right)$ in a soil is related to the $q_{\mathrm{c}}$ measured in a CPT. The findings of [14] for cavity expansions in unsaturated Lyell silty sand are adopted.

[14] studied the effects of three different drainage conditions (constant suction, constant moisture content and constant $\chi s$ ) on $\sigma_{\mathrm{L}}$. For each drainage condition they observed that a significant change of void ratio occurs around an expanding cavity in the unsaturated soil, and analogously occurs around the tip of a penetrating cone. They found that, for a constant moisture content condition and full hydro-mechanical coupling, the changes to $\chi$ and $s$ mostly counteract each other and constant $\chi S$ may be assumed to give a reasonable approximation. For constant moisture content an increase in $e$ results in a decrease in $s$ but an increase in $\chi$ and vice versa. The assumption of $\chi s$ being a constant will be used to simplify interpretation of the CPT results.

[14] also studied the influence of where the initial hydraulic state was located on the SWCC on $\sigma_{\mathrm{L}}$. They found when results were presented in the $p_{0}^{\prime} \sim \sigma_{\mathrm{L}}$ plane, where $p_{0}^{\prime}$ is the initial mean effective stress in the soil, unique relationships were observed irrespective of the initial hydraulic state locations. This observation will also be used to simplify interpretation of the CPT results.

The initial $p_{0}^{\prime}$ and $e_{0}$ values used in generating the cavity expansion results are shown in Figure 3. Also shown are the limiting isotropic compression lines (LICLs) determined using a range of laboratory compression testing ([14]).

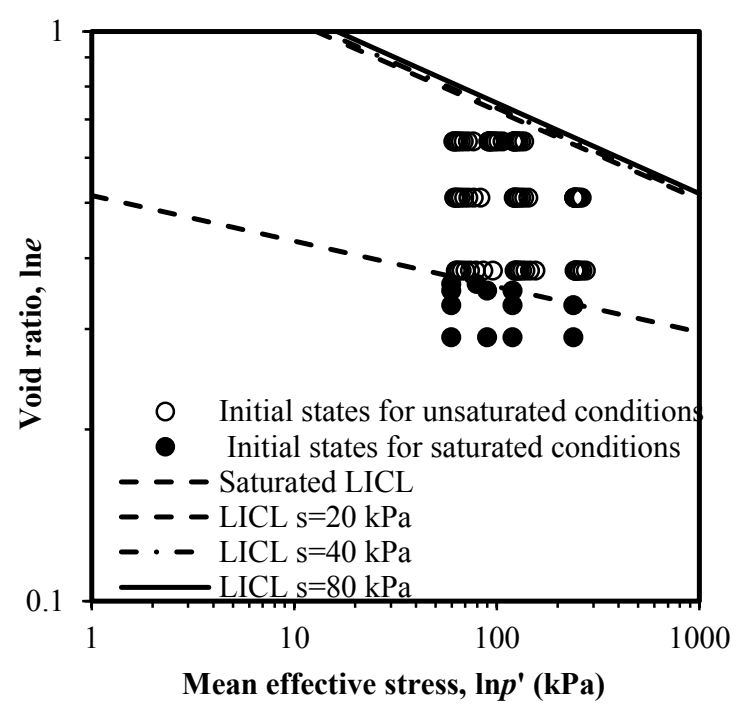

Figure 3. Initial states for the cavity expansion analysis and associated LICLs.

Results for expanding spherical cavities in saturated Lyell silty sand under drained conditions are shown in Figure 4.

Fitted to the results in Figure 4 is a correlation, similar to that of [15], relating $\sigma_{\mathrm{L}}$ to $D_{\mathrm{r}}$ and $p_{0}^{\prime}$, with errors less than $5 \%$. The correlation is:

$$
\sigma_{\mathrm{L}}=0.26 p_{0}^{\prime 0.65} \exp \left(6.18 D_{\mathrm{r}}\right)
$$

Notice that $\sigma_{\mathrm{L}} \approx \sigma_{\mathrm{L}}^{\prime}$ since $\sigma_{\mathrm{L}}>u_{\mathrm{w}}$.

Results for expanding spherical cavities under constant $\chi s$ conditions can be fitted with a modified correlation, with errors less than $15 \%$, as shown in Figure 5. The modified correlation is:

$$
\sigma_{\mathrm{L}}=18 p_{0}^{\prime}{ }^{0.65} \exp \left(2.6 D_{\mathrm{r}}\right)
$$

Significant differences between Equation (6) and (7) are due to the presence of suction hardening. On the cavity wall, where the soil is at a critical state, significantly elevated pressures act for an unsaturated 
condition due to the suction induced shifts of the LICLs and CSLs in the $\ln e \sim \ln p^{\prime}$ plane $([4,14])$.

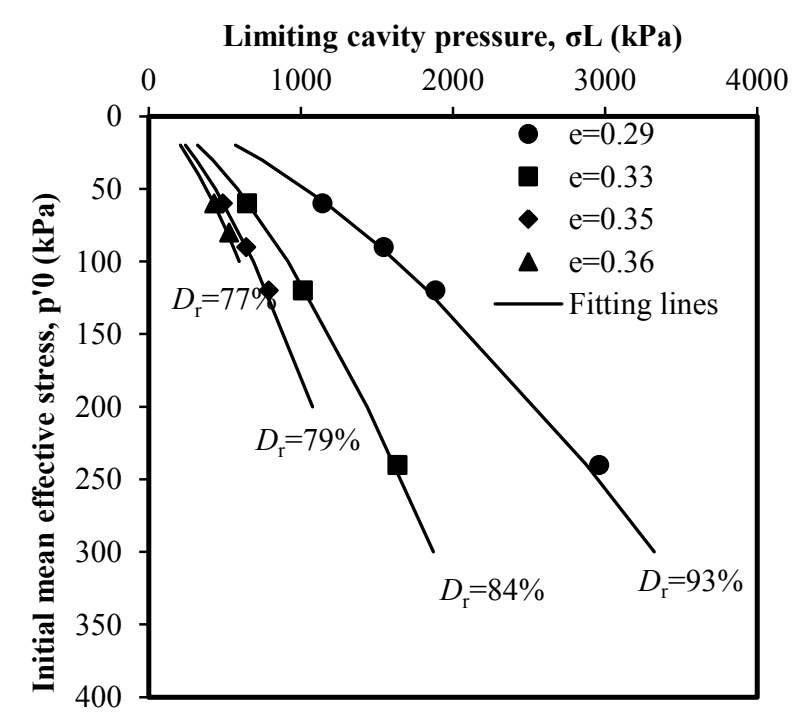

Figure 4 . The limiting cavity pressure $\left(\sigma_{\mathrm{L}}\right)$ from saturated drained spherical cavity expansion analysis fitted with Equation (6).

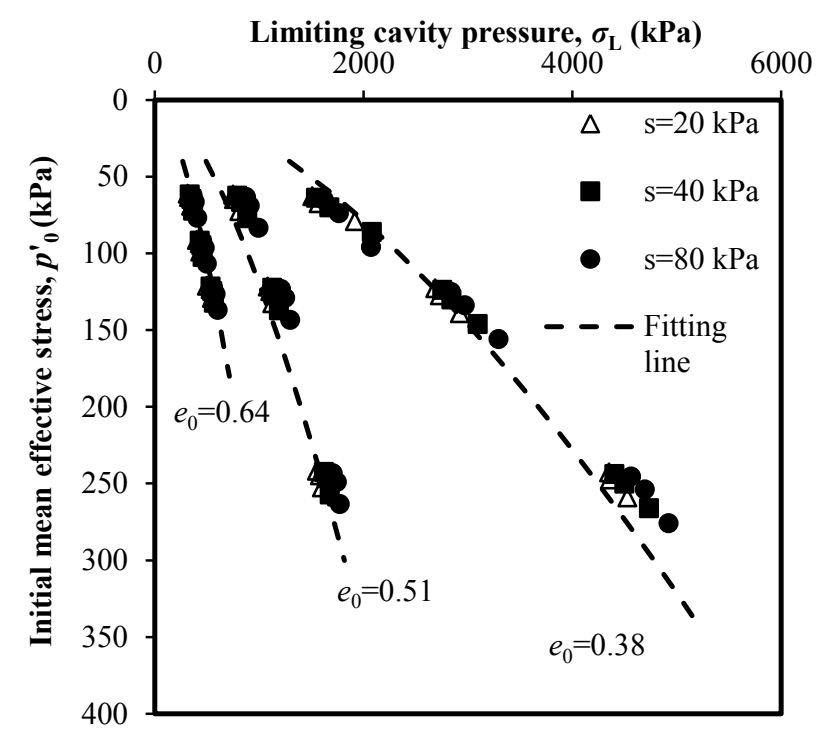

Figure 5. The limiting cavity pressure $\sigma_{\mathrm{L}}$ fitted with Equation 7 .

Shown in Figure 6 is $\sigma_{\mathrm{L}}$ divided by $p_{0}{ }_{0}^{0.65}$ versus $D_{\mathrm{r}}$ for spherical cavity expansions in saturated and unsaturated Lyell silty sand. This Figure illustrates the effect of suction hardening. As can be seen, for unsaturated conditions, the results for different suction values are very similar. However, there is a large difference between results for unsaturated and saturated conditions. This is due to suction hardening and the suction dependent shifts of the LICLs and CSLs, features incorporated in the constitutive model used to generate the cavity expansion results.

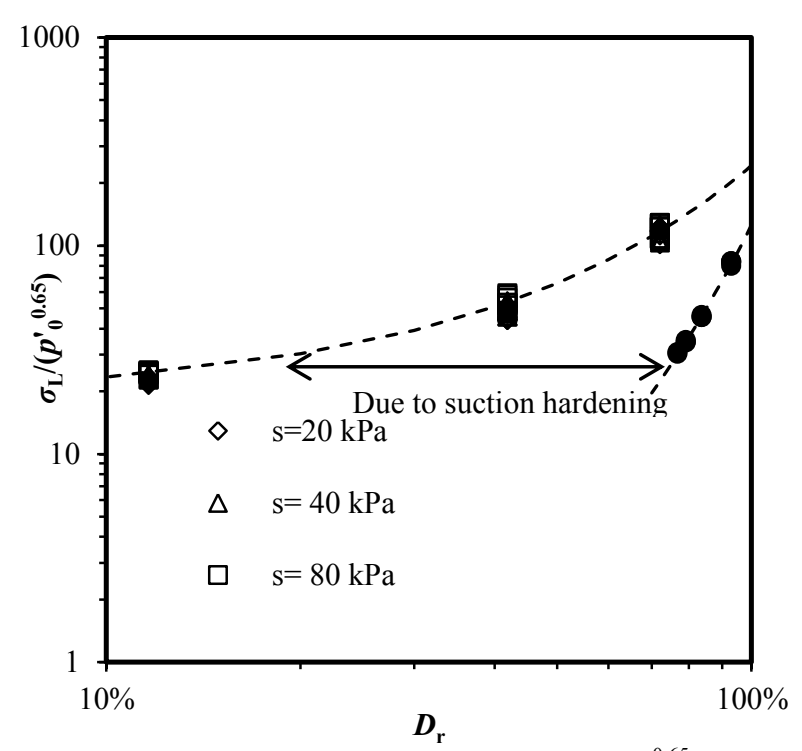

Figure 6 . Limiting cavity pressure $\sigma_{\mathrm{L}}$ divided by $p_{0}^{\prime 0.65}$ versus $D_{\mathrm{r}}$ for spherical cavity expansions conceptual illustration of suction hardening effects.

\subsection{Comparison of cavity expansion results with CPT results}

Cavity expansion analysis results were generated for soil states used in the calibration chamber tests. It is acknowledged that the cone penetration resistance measured in the calibration chamber can be slightly different from that measured in the field. Several methods have been proposed to account for the finite chamber size effect. Some are empirical (e.g., [16]) and some are numerical or analytical (e.g., [17-18]). The vertical stress which goes into the computation of the initial mean net stress and then to compute the cavity wall pressures is corrected through ([19]):

$$
\sigma_{\mathrm{vc}}=\sigma_{\mathrm{v}}-\frac{q_{\mathrm{c}}}{\left(R_{\mathrm{D}}\right)^{2}}
$$

where $\sigma_{\mathrm{v}}$ is the applied vertical pressure at the chamber base and $R_{\mathrm{D}}$ is the ratio of diameters for the chamber and cone, being $460 / 16=28.8$ here.

Following [16], a linear proportionality between $q_{\mathrm{c}}$ and $\sigma_{\mathrm{L}}$ can be observed, as shown in Figure 7, and for unsaturated Lyell silty sand and void ratios ranging from 0.51 to 0.65 is $q_{\mathrm{c}}=9 \sigma_{\mathrm{L}}$. It follows that:

$$
q_{\mathrm{c}}=162\left(p_{0}+\chi s\right)^{0.65} \exp \left[2.6 D_{\mathrm{r}}\right]
$$

As shown in Figure 8 and Figure 9 the error associated with Equation (10) to obtain $q_{\mathrm{c}}$ is less than $30 \%$. For unsaturated Lyell silty sand a rearranged Equation (10) gives:

$$
D_{r}=\frac{1}{2.6} \ln \left[\frac{q_{\mathrm{c}}}{162\left(p_{0}+\chi s\right)^{0.65}}\right]
$$

This enables determination of $D_{\mathrm{r}}$ from $q_{\mathrm{c}}, p_{0}$ and $\chi s$. 


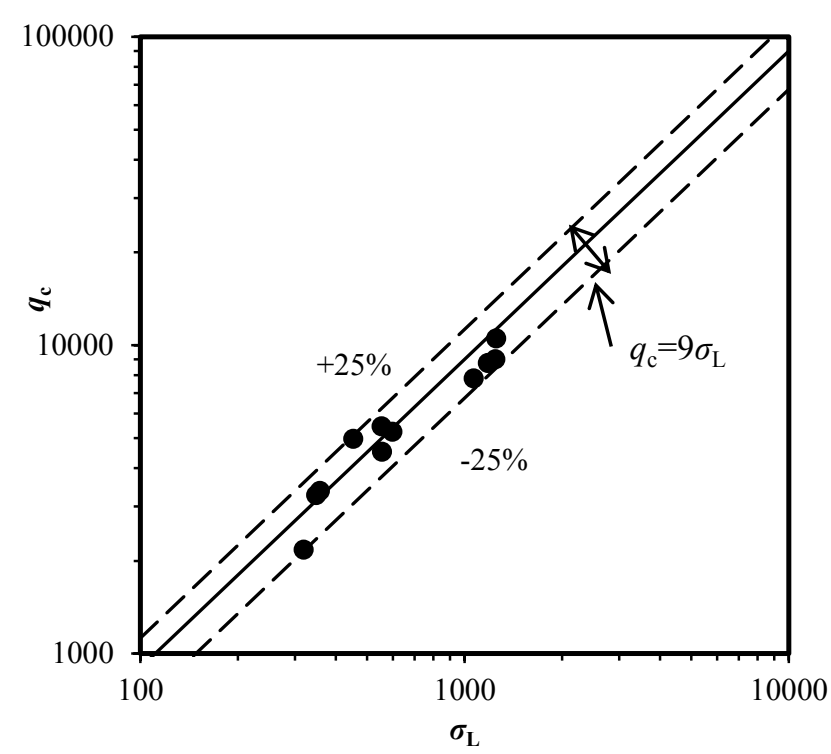

Figure 7. A possible correlation between $q_{\mathrm{c}}$ measured from chamber and $\sigma_{\mathrm{L}}$ from spherical cavity expansion.

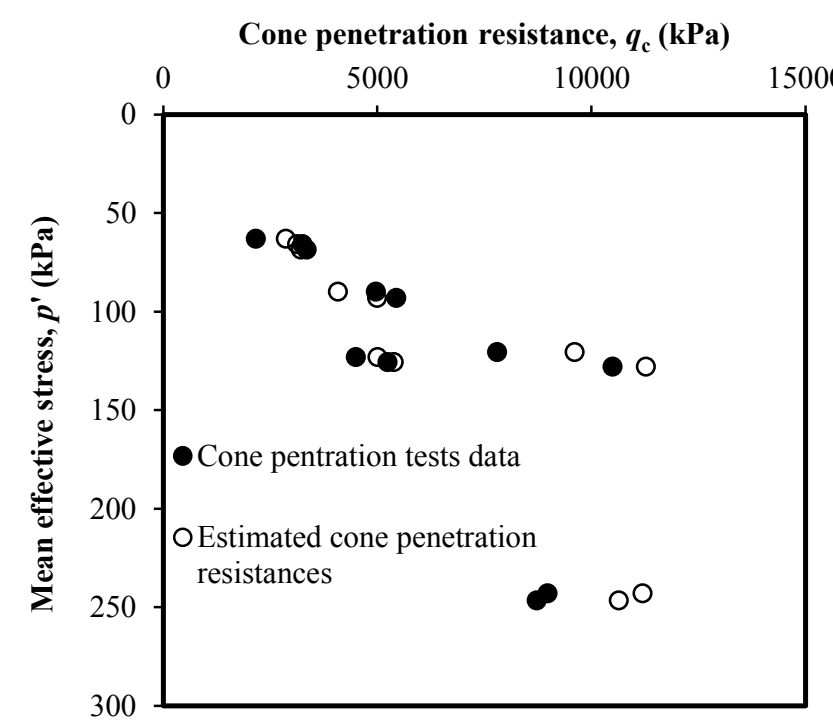

Figure 8. Comparison of cavity expansion data and estimations using Equation (10).

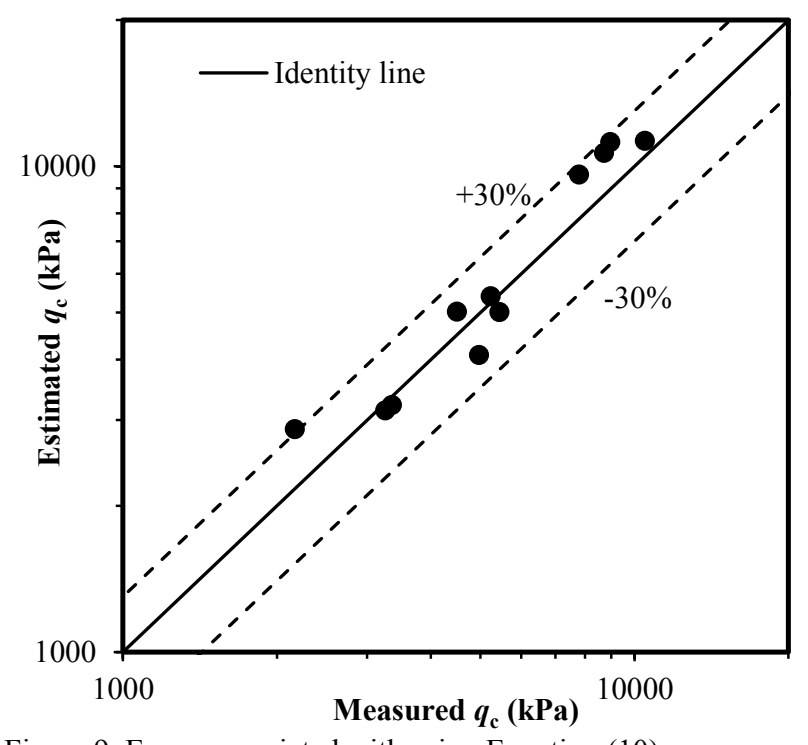

Figure 9. Errors associated with using Equation (10).

\subsection{Example of application}

A change in suction will alter the strength of the soil. Ignoring the effect of suction may lead to an overestimation of $D_{\mathrm{r}}$ and the corresponding $\phi_{\mathrm{p}}^{\prime}$ from Equation (6). A descriptive example is now used to highlight this. Suppose $q_{\mathrm{c}}=5530 \mathrm{kPa}$ was measured at a location in a profile of Lyell silty sand where $p_{0}=25 \mathrm{kPa}$ and $\chi s=25 \mathrm{kPa}$. $D_{\mathrm{r}}=0.38$ is obtained from Equation (11) which corresponds to $\phi_{\mathrm{p}}^{\prime}=39.1^{\circ}$ (Equation (6)). If suction influence is ignored and $p_{0}^{\prime}=25 \mathrm{kPa}$ is incorrectly assumed then $D_{\mathrm{r}}=0.55$ is obtained corresponding to $\phi_{\mathrm{p}}^{\prime}=43.1^{\circ}$ (an overestimation of $4.0^{\circ}$ ).

The correlation between $q_{\mathrm{c}}, D_{\mathrm{r}}$ and $p_{0}^{\prime}$ presented here for unsaturated Lyell silty sand is similar to those presented by [15] and [2] for saturated and unsaturated clean sands, e.g. Sydney sand. As Sydney sand does not exhibit suction hardening the same correlation applies for saturated and unsaturated conditions. However, for soils which contain a significant amount of fines, like Lyell silty sand, a correlation which works for unsaturated conditions will not work for saturated conditions. This is due to the very different soil responses around the cone tip for saturated and unsaturated conditions and, in some cases, to the presence of suction hardening.

\section{Conclusions}

The results of laboratory-controlled CPTs were presented for unsaturated Lyell silty sand, a soil which exhibits suction hardening. The CPTs were conducted to study the effects of suction on cone penetration resistance for a range of confining stresses and densities.

The data was interpreted taking guidance from results of a recent cavity expansion analysis in Lyell silty sand. The cavity expansion analysis indicated a constant $\chi s$ condition can be assumed to simplify the data interpretation without loss of significant accuracy. The cavity expansion analysis also indicated that the location of the initial hydraulic state on the SWCC has negligible influence on the relationship linking $p_{0}^{\prime}$ to $q_{\mathrm{c}}$. 
For an isotropic net confining stress of $60 \mathrm{kPa}$ a suction of $72 \mathrm{kPa}$ was associated with a $q_{\mathrm{c}} 55 \%$ larger than the value for a suction of $24 \mathrm{kPa}$. For samples subjected to an isotropic net confining stress of $120 \mathrm{kPa}$ a suction increase from $13 \mathrm{kPa}$ to $55 \mathrm{kPa}$ caused an increase in $q_{\mathrm{c}}$ by about $35 \%$. There was a diminishing affect of suction on $q_{\mathrm{c}}$ as net confining stress increased.

A correlation was introduced, inspired by cavity expansion results and the observation of a strong linear proportionality between $q_{\mathrm{c}}$ and the wall pressures of expanding spherical cavities. The correlation links $q_{\mathrm{c}}$ to $p_{0}$ and $\chi S$ (through $p_{0}^{\prime}$ ) and $D_{\mathrm{r}}$. It resembles other correlations proposed for saturated and poorly graded sands. The resemblance is due to cone penetration in unsaturated Lyell silty sand being accompanied by significant soil deformation around the cone tip, as also occurs around penetrations in saturated poorly graded sands. However, a rather different correlation would be needed for saturated Lyell silty sand in which penetration would occur under undrained conditions.

An example was given to demonstrate the effect of suction. It was found that failing to account for the effect of suction may result in significant overestimation of relative density and peak friction angle.

The results and conclusions presented in this paper are only relevant to unsaturated Lyell silty sand. Many further studies of the CPT in a wider range of unsaturated soils are needed before CPT interpretation methods can be generalised.

\section{References}

1. T. Lunne, P.K. Robertson, J.M. Powell, Cone penetration testing in geotechnical practice. Blackie Academic \& Professional, London (1997)

2. M. Pournaghiazar, A.R. Russell, N. Khalili, Geotechnique 63(14): 1209-1220 (2013)
3. B. Lehane, M.A. Ismail, M. Fahey. Geotechnique 54(3): 215-218 (2004)

4. A.R. Russell, N. Khalili. Comput. Mech 37(4): 311-330 (2006)

5. A.R. Russell, O.Buzzi, Geotechnique 62(3): 269274 (2012)

6. A.R. Russell, Geotechnique 64(5): 379-390 (2014)

7. A.W. Bishop, The principle of effective stress. Teknisk Ukeblad. 106: 859-863 (1959)

8. N. Khalili, M.A. Habte, S. Zargarbashi, Comput. Geotech. 35(6): 872-889 (2008)

9. N. Khalili, S. Zargarbashi, Geotechnique, 60(9): 729-734 (2010)

10. M. Pournaghiazar, A.R. Russell, N. Khalili, Can. Geotech. J. 48(2):314-321 (2011)

11. H. Yang, A.R. Russell, In Advances in Unsat. soils pp: 191-197 (2013)

12. H. Yang, A.R. Russell. Can. Geotech. J. 53(3): 431444 (2016).

13. H. Yang, A. Khoshghalb, A.R. Russell, Geotech. Lett. 4: 1-10 (2014)

14. H. Yang, A.R. Russell. Int. J. Numer. Anal. Met. 39(18): 1975-2016 (2015)

15. G. Baldi, R. Bellotti, V. Ghionna, M. Jamiolkowski, E. Pasqualini, In Proceedings of the Fourth International Geotechnical Seminar pp. 143-156 (1986)

16. R. Cudmani, V.A. Osinov, Can. Geotech. J. 38(3): 622-638 (2001)

17. R. Salgado, J. Mitchell, M. Jamiolkowski, J. Geotech. Geoenviron. 124(9): 878-888 (1998)

18. M. Pournaghiazar, A.R. Russell, N. Khalili, Int. J. Numer. Anal. Met. 37(4): 331-352 (2013)

19. L.D. Wesley, Geotechnique 52 (4): 289-293 (2002) 